\title{
Avtorske pravice v češki literaturi na prelomu 19. in 20. stoletja: Jiráskov spor za Pasjeglavce
}

Miloš Zelenka

Oddelek za srednjeevropske jezike in kulture Univerze Konštantína Filozofa v Nitri Dražovská 4, 94974 Nitra, Slovaška

https://orcid.org/0000-0002-4049-3263

zelenka.milos@centrum.cz

Razprava obravnava teoretske in zgodovinske vidike avtorskega prava $v$ obdobju Habsburške monarhije na primeru nedovoljene gledališke priredbe romana Aloisa Jiráska Pasjeglavci (Psohlavci), ki jo je 1899 pod naslovom Jan Sladký Kozina napisal in uprizoril Jan Baptist Kühnl (1849-1904), dramatik, prevajalec in eden prvih plagiatorjev v zgodovini češke književnosti. Leta 1899 je Jirásek dobil tožbo proti nezakoniti uprizoritvi na podlagi cesarskega zakona št. 197/1895 o zaščiti avtorskih pravic za literarna, umetniška in fotografska dela, ki je nadgradil cesarski patent iz leta 1846 (nekatere formulacijev njem so prešle v avtorsko pravo neodvisne Češkoslovaške). Toda leta 1920 sta Kühnlovi vdova Marie in hči Marie Luisa igro izdali v knjižni obliki, pri čemer sta besedilo iz leta 1899 le jezikouno posodobili. Jirásek je l. 1921 dobil še eno tožbo proti plagiatorstuu, ki kaže na pomen avtorskih pravic kot manifestacije duhoune, nesnoune lastnine, ki jo je treba pravno zašcititi, zliterarnega vidika pa demonstrira primer plagiata kot neinventivne imitacije, ki si izposoja "celotno zgradbo, romaneskno zgodbo in posamezne sestavine literarnega dela.

Ključne besede: literatura in pravo / češka književnost / literarna zgodovina / avtorske pravice / Jirásek, Alois: Pasjeglavci / gledališke priredbe / Kühnl, Jan Baptist / plagiat

Problematika avtorskih pravic, ki se nanašajo na besedno umetnost, spada med slabše obdelana vprašanja sociologije literarne kulture, a je v povezavi s kategorijo avtorja še vedno aktualna. Čeprav se z vidika recepcijske in strukturalne estetike delo kot "znak» in "estetski objekt" po svojem nastanku odcepi od svojega "stvaritelja», "pobudnika« oziroma "avtorja in njegove ontološke biti ter postane nekakšna "javna lastnina«, avtorske pravice vendarle še služijo individualnim interesom posameznika (Pospíšil in Zelenka 7-51). To eksplicitno priča o dejstvu, da besedno delo v svoji prvotni, materializirani podobi, tj. delo 
kot "stvar«, služi za zadovoljevanje ekonomskih potreb. Delo torej postane »blago « $\mathrm{z}$ ekonomsko menjalno vrednostjo, ki jo sicer ustvarja trg, a v nasprotju z delom kot "znakom" še vedno pripada avtorju kot obvezna oblika njegove intelektualne lastnine. Zato je logično, da se problematika avtorskih pravic razkrije šele z razvojem družbene mobilnosti meščanske družbe. V srednjeevropskem kontekstu so se avtorske pravice sicer uveljavile $\mathrm{v}$ obdobju romantike, ki je poudarjala ustvarjalno osebnost, vendar pa so se že od konca renesančne dobe v zametkih udejanjale npr. v obliki založniških pogodb med avtorjem in njegovim založnikom ali preko privilegijev in koncesij za časovno omejeno uprizarjanje gledaliških iger in opernih predstav (Hermann-Otavský).

Prvi zakon v habsburški monarhiji, ki je kompleksno urejal avtorske pravice, je bil cesarski patent 19. oktobra 1846, ki je nedvoumno določal, da tvorijo sadovi intelektualnega dela zakonsko zaščiteno lastnino in da mora biti delo zaščiteno od trenutka geneze. Že v tem zakonu je bil vsebovan princip teritorialnosti, po katerem se je evropsko pravo razlikovalo od angloameriškega pravnega sistema. Ni bilo pomembno državljanstvo avtorjev, ampak mesto, kjer je delo izšlo. Ta dvojnost obstaja do danes, kajti po ameriški tradiciji, osnovani na naravnopravni teoriji (author's rights), je besedno delo izraz konkretnega človeškega subjekta z vidika njegove edinstvenosti (glej Sýkorová). Povedano drugače: delo kot izraz osebnosti avtorja ne sme biti odtujeno, ker je položaj avtorja nad javnim interesom. Po angloameriški pravni doktrini (common law copyright) pa je družbeni interes utilitarno nadrejen interesom avtorja besedila, zato je avtor poleg fizične osebe lahko tudi pravni subjekt, ki določa lastninski princip, to pomeni, da se uveljavlja sistem državno priznanih avtorskih pogodb.

Drugi, bistveno pomembnejši zakon o avtorskih pravicah v habsburški monarhiji, katerega nekatere določbe so prešle tudi v obstoječi [češki, op. prev.] pravni red, je Zakon o izvornih pravicah do literarnih, umetniških in fotografskih del št. 197 cesarskega zakonika z dne 26. decembra 1895 , ki se je navezal na mednarodno sprejeto, t. i. Bernsko konvencijo z dne 9. septembra 1886 za zaščito literarnih in umetniških del ter spomenikov ter nemški avtorski zakon iz leta 1870 . Ta zakon, po katerem je bil po letu 1918 napisan prvi avtorski zakon medvojne Češkoslovaške republike, je vseboval 68 členov v petih razdelkih: $\mathrm{v}$ celoti se je odzval na razmah umetniške ustvarjalnosti konca 19. stoletja kot posebne oblike intelektualne lastnine, ki ima specifičen status in jo je možno pravno varovati. Avtorskih pravic v primerjavi s cesarskim patentom iz leta 1846 ne pojmuje samo kot skupek razpolagalnih (lastninskih) pravic, ampak ima njihovo kršenje tudi za poseg v skupek osebnostnih 
pravic. Razloga za pripravo novega, ne zgolj noveliranega zakona sta bila količinski razmah literarne produkcije $\mathrm{v}$ drugi polovici 19. stoletja in tehnični napredek $\mathrm{v}$ izpopolnjevanju reprodukcijskih metod. Zakon, ki je sicer hotel zaščititi avtorja v njegovih "materialnih" in "idealnih" potrebah, je obenem iskal praktični kompromis med interesi avtorja, založbe in razširjajoče se bralske skupnosti (Kadlec). Ugotavljal je, da ima avtor pravico ekonomsko izkoristiti proizvod svojega intelektualnega dela, vendar je to lahko v neskladju z interesom bralske javnosti, ki želi v čim večji meri in brez omejitev sprejemati literarno delo. ${ }^{1}$

Zakon je zamejil avtorske pravice kot obliko osebnih pravic, ki imajo skupen značaj ne glede na vrsto ustvarjalca, pa naj gre za skladatelja, likovnega umetnika ali pisatelja. Čeprav je zakon določal ustrezno zaščito avtorstva, ni podal točne definicije teh pravic in je dopuščal, da sodniki na podlagi strokovnih spoznanj in glede na značaj konkretnega postopka določijo njihovo vsebino in obseg.

V srednjeevropski tradiciji (z izjemo nekdanjega Nemškega cesarstva s Prusijo) pojem plagiata še ni bil jasno definiran; zato je zakon spregovoril samo o namerni prezentaciji tujega intelektualnega dela, delno ali v celoti posnetega, kot lastne stvaritve. Obvezni pogoj za presojo je, da se mora pravna zaščita vedno nanašati le na delo, nastalo kot "edinstven" rezultat ustvarjalne dejavnosti. Ustvarjalčeve pravice so bile celostno razumljene kot pravna možnost avtorja (ali njegovega pravnega naslednika), da z literarnim delom razpolaga kot z materialno "dobrino« oziroma »stvarjo" pod pogoji, da je avtor po vsebinski in formalni strani opravil osebno, edinstveno intelektualno delo, h kateremu lahko sodi tudi fizična dejavnost, kadar npr. pisatelj v svojem besedilu uresničuje misli, prenesene iz notranjega $\mathrm{v}$ zunanji svet. $\mathrm{Na}$ besedno delo avtorja ne vežejo le gmotni interesi, temveč tudi osebni. Zato je plagiatorja mogoče tožiti ne le za povzročeno materialno škodo, temveč tudi za motenje osebnih interesov, med drugim na primer zato, da bi se preprečila neestetska sprememba originala, ki bi škodovala pisateljevemu imenu. Po zakonu se delo s samo realizacijo sicer odtrga od svojega avtorja, vendar se avtorjevi osebni interesi ohranjajo tudi po nastanku in realizaciji dela, zato mora biti besedilo ustrezno zaščiteno pred izkoriščanjem. Pri dramskih izvedbah se na primer omenja formalno in stvarno tolmačenje dela; založnik zato brez soglasja avtorja $\mathrm{v}$ delu ne sme ničesar spremeniti.

${ }^{1}$ Češki pravnik Karel Adámek je v zvezi s tem konec 19. stoletja menil, da »se ni enostavno odločiti tako, [...] da bi bila avtorju zagotovljena pripadajoča mu nagrada in njegovi osebni interesi ne bi bili kršeni, obenem pa tudi občinstvu ne bi bila radost ob duhovnih dobrinah otežena bolj, kot zahteva ozir na avtorja« (8). 
Pri specifikaciji avtorskih pravic na literarnih delih (člen 23) je zakon poudaril, da te pravice obsegajo možnost in obveznost izdana in neizdana besedila objaviti, razmnoževati in prevajati, to je razširjati. Zakon obravnava tudi t. i. piratski natis, ki ga lahko zagreši neupravičeni prireditelj tujega dela ali pa gre za nedovoljen izvleček. Za piratskega velja tudi ponatis, če je naklada višja od pogodbeno dogovorjene. 23. člen je določil, da ima avtor gledališke igre izključno pravico za njeno javno uprizarjanje, tudi če si je pri objavi ni izrecno pridržal. Kot izjema je veljala zasebna ustna reprodukcija besedila.

Zakon je v 25. členu v imenu javnega interesa dopuščal tretjim osebam dobesedno navajati posamezna mesta ali manjše odlomke, ni pa natančno določal obsega dovoljenega prevzemanja. V praksi je bilo priporočeno kot maksimum prevzeti štiri strani iz ene avtorske pole in tolerirati ponatis, ki ne presega ene avtorske pole. Prav tako je bilo dovoljeno iz del več avtorjev urediti zbirko za šolske ali verske potrebe (npr. cerkveno pesmarico), pri čemer je bil urednik obvezan, da navede avtorja ali vir. Kar se tiče prevoda že izdanega dela, ima izključne pravice avtor samo tedaj, kadar si je pravico do prevoda na naslovni strani ali v predgovoru izrecno pridržal; ta pravica mu je pripadala pet let od izdaje originala.

Posebno pozornost je zakon posvetil določitvi avtorja dela, kar je običajno sam pisatelj, pri čemer pa ni pomembno, ali je delo sam zapisal. Avtor besedila je samo tisti, s čigar duhovno dejavnostjo je delo dokazano nastalo. Glede na zahtevnost dokazovanja je zakon izhajal iz domneve, da za avtorja izdanega dela velja tisti, čigar pravo ime je bilo pri izdaji navedeno v naslovu, predgovoru ali posvetilu. Tudi v primeru anonimnosti ali psevdonima je pisec ostal subjekt avtorskih pravic (člen 11). Zakon je $\mathrm{v}$ ta namen pri ministrstvu za trgovino vzpostavil t. i. avtorski seznam literarnih in umetniških del, izdanih anonimno ali pod psevdonimom. Vanj so bila zaradi dokazljivosti avtorstva vpisana prava imena po določeni shemi: ime, delovno mesto, prebivališče, državljanstvo, točna oznaka dela in vrste dela (naslov, število zvezkov, število strani ipd.). Za najavo vpogleda se je plačalo pet goldinarjev, pri čemer je imel vsak državljan pravico prositi tudi za prepis. Treba je opozoriti, da zaradi varovanja osebnosti in pravega imena avtorja urad tem prošnjam v praksi zvečine ni ugodil.

Zelo moderno in napredno je bilo $\mathrm{v}$ avtorskem zakonu razlikovanje med avtorjem in lastnikom dela. Lastniška pravica je bila materialna, avtorska pravica pa je bila dojeta širše, saj poleg svojega "materialnega značaja zajema tudi "osebno potezo«. Ustvarjalčeve pravice veljajo za celotno delo in njegove dele. Med literarna dela so kot predmet ustvar- 
jalčevih pravic v členu 4 spadale knjige, brošure, revije, pa tudi zbirke pisem in druga slovstvena dela. Iz tega so bili razumljivo izvzeti obrazci, odloki, navodila ipd. Zanimivo je, da zakon ni omenjal rokopisov, kar je pomenilo, da je avtorske pravice vezal predvsem na dokončana dela, po možnosti objavljena in delujoča v literarnem življenju, medtem ko je osnutek besedila oz. pretekst v obliki rokopisa razumel v sklopu procesa pisanja kot materializiran, nezaključen skupek besedilnih možnosti.

Iz tega so izhajala tudi določila o začetku in trajanju avtorskih pravic, kar se ni smelo mešati z izidom dela. Avtorske pravice so namreč izhajale iz dokončne realizacije dela, ki je lahko veljalo za dokončano, čeprav ni bilo zapisano. ${ }^{2}$ Pisci zakona so se zavedali, kako zahtevno je dokazovanje avtorstva. V spornih primerih je zato sodišče smelo upoštevati dodatne, posredne dokaze, ki bi jih predložil avtor - npr. da je že prej sporočil znancem, da je na tekstu začel delati ali pa jim je zaupal rokopis v prvo branje. 6. člen zakona je upošteval tudi posebnosti literarnih in gledaliških del. Slednja niso nujno natisnjena (npr. dramsko besedilo je bilo izdano šele po uprizoritvi), a vseeno veljajo kot objavljena ( $\mathrm{z}$ datumom prve gledališke uprizoritve).

Zakon je v primeru kršitev, tako imenovanih "posegov" v avtorske pravice, predvideval sankcije. Razlikoval je med blažjim prestopkom in hujšo kršitvijo. Za prestopek, za katerega je bila predvidena kazen pet do sto goldinarjev, je veljala opustitev navedbe avtorja ali vira. Zgolj prevzem naslova, četudi nameren, še ni kršil avtorskih pravic. Kršitev, za katero je bila predvidena kazen od sto do dva tisoč goldinarjev ali zapor od enega do šestih mesecev, je nastala, če je storilec zavedno ali nezavedno tuje delo opremil s svojim imenom in ga je $z$ namenom finančnega dobička nezakonito razširjal, izdajal oziroma poslal v javni obtok. Oškodovani avtor je imel v primeru kazenskega postopka pravico še pred razglasitvijo razsodbe prositi, da se nepravno razširjani teksti in rokopisi zaplenijo in sprejmejo v sodno hrambo. Po obsodbi nezakonite izdaje je morala biti ta zasežena, oškodovani pa je imel pravico zahtevati javno opravičilo krivca ter nadomestilo škode in izgubljenega dobička $\mathrm{v}$ obliki sorazmerne denarne vsote. $\mathrm{V}$ primeru prestopka je lahko o kršitvah avtorskih pravic odločalo tudi civilno sodišče, ki je presojalo o obsegu nastale materialne škode in subjektivnega

${ }^{2}$ Karel Adámek v komentarjih k uporabi avtorskega zakona omenja primer, da pesnik sestavi pesem, a je ne napiše, pač pa njeno materializirano izvršitev kot virtualen tekst shrani v svoj spomin (80-82). Po njegovem javnem recitiranju pesmi bi jo lahko kak poslušalec anonimno ali pod svojim imenom izdal kot njen avtor. Toda ta razlaga ne zdrži, kajti dikcija zakona jasno določa, da je avtor pesmi z zakonskimi pravicami pesnik, čeprav pesmi ni lastnoročno napisal in je niti ni nameraval izdati. 
oškodovanja avtorja. Ker od slehernega sodnika ni bilo pričakovati strokovnih znanj o posameznih umetnostih, je zakon v 65. členu pooblastil cesarsko vlado oziroma pravosodno ministrstvo, da v sodelovanju z ministrstvom za kulturo in izobraževanje oblikujeta t. i. izvedenske odbore iz vrst priznanih umetnikov, znanstvenikov, novinarjev in drugih. Odbori za literarno področje so bili v habsburški monarhiji ustanovljeni v Pragi, Lvovu, Trstu in na Dunaju. Na pobudo sodišča so morali priskrbeti objektivna mnenja o problematičnih, večinoma strokovno-tehničnih vidikih umetniške ustvarjalnosti. Vsak odbor je moral imeti poleg predsednika tudi od šest do deset članov, ki jih je imenovalo ministrstvo za kulturo in izobraževanje za dobo šestih let. Odbor je po izvedenski prisegi večinoma deloval tako, da je predsednik imenoval dva poročevalca, ki sta samostojno podala vsak svoje mnenje o primeru kršitve avtorskih pravic, potem pa se je v skupini o tem glasovalo.

Za češke dežele je bil izvedenski odbor za literaturo sicer nedvomno imenovan, a se brez poglobljene arhivske raziskave ne da natančno popisati njegove sestave in obsega delovanja. V zapuščini Aloisa Jiráska (1851-1930), enega najslavnejših čeških pisateljev in ustanovitelja moderne historične proze $\mathrm{v}$ duhu kritičnega realizma, se nahaja pet zapisov c. kr. namestništva na Češkem in prezidija cesarsko-kraljevega deželnega sodišča iz obdobja 1897-1905 o njegovem članstvu v skupini izvedencev za področje avtorskih pravic za literaturo. ${ }^{3}$ Prav Jirásek je bil tisti, ki je med češkimi pisatelji očitno prvi izkoristil pravno pot $\mathrm{v}$ zadevi kršitve svojih avtorskih pravic iz leta 1895 (Filová) zaradi nedovoljene priredbe svojega ključnega dela Pasjeglavci. Ti se namreč po umetniški in recepcijski plati uvrščajo med najuspešnejša avtorjeva dela.

Pasjeglavci simbolizirajo neuspešen boj čeških politikov za t. i. zgodovinske pravice. Leta 1879 se je staročeška stranka ob boku mladočeške po šestnajstih letih neuspešne rezistence vrnila v dunajski parlament, vendar jim tudi tam ni uspelo uveljaviti federalizacije monarhije in kronanja cesarja Franca Jožefa I. za češkega kralja. Literatura se je subjektivno odzivala na pesimizem češke družbe $\mathrm{z}$ aktualizacijo pogleda na slavno preteklost, v katero se je uvrščala tudi tema kmečkih uporov. Jiráskovi Pasjeglavci v obliki zgodovinske epike poudarjajo boj za narodne in socialne pravice (Špét 144). Dramatični konflikt med fevdalno krutostjo in uporništvom češkega vaškega prebivalstva se bliža monumentalni baladnosti (Moravec 90). Ta patos se kaže v podobi stopnjevanega in vnaprej izgubljenega boja prebivalcev Chodskega z

${ }^{3}$ Shranjeno v Literarnem arhivu Spomenika narodnega pismenstva v Pragi, št. sign. 11033-11037 (zapuščina A. J.). 
gospoščino, vznemirljivo ozračje pa še zaostri romantično izpostavljeni motiv nadnaravne »božje sodbe«(Simon 75-78; Hodura 87-94).

Jirásek je Pasjeglavce pisal v letih 1883-1884, objavil jih je v reviji Květy leta 1884 (knjižno 1886). Kot vsebinsko osnovo je izbral ožje regionalni zgodovinski dogodek $\mathrm{z}$ vsenarodnim dometom, in sicer boj svobodnih chodskih kmetov po njihovi neuspešni sodni pravdi s svojim gospodom Vilémom Lammingerjem. V tem konfliktu so kmetje izgubili svoje privilegije, ki so jih v preteklosti dobili od čeških kraljev za varovanje deželnih meja (Kramařík).

Jiráskovo stališče do chodskega uporništva se je podredilo ustvarjalni nameri, osredotočeni na umetniško upodobitev zaključne faze socialnega boja za češke zgodovinske pravice, ponižane zaradi Bele gore. ${ }^{4}$ Zato je uporu kljub njegovemu regionalnemu značaju vtisnil nadčasovno simboliko: ob strani je pustil ne le religiozne motive (zmagoviti katolicizem proti zatiranemu protestantizmu), temveč tudi narodnostne (češki podložniki in nemška oblast), poudaril pa je socialne. Glavni lik, svobodnega kmeta Jana Kozino, je Jirásek izpostavil kot tip nepatetičnega junaka, ki ga šele zgodovinske okoliščine postavijo na čelo upora. S tem je Jirásek kompozicijsko in psihološko motiviral preporod preudarnega junaka v ozaveščenega vodjo upornikov: skozi besedilo romana se namreč od uvodne scene preliva motiv Kozinove družinske sreče, ki zasveti vedno v zgodovinsko pomembnih trenutkih (Cuřín 32). Večina literarnih likov je prikazana v dveh perspektivah: ne le v konfrontaciji z javnim dogajanjem, temveč tudi v zasebnosti, $\mathrm{v}$ intimnem krogu z ženo ali ljubljeno. Zgodovinski motivi postopno odstopajo prostor prikazu ljudskega kolektiva, ki demonstrira svojo moralno moč in zgodovinski optimizem.

Ker so Jiráskovi Pasjeglavci že v 19. stoletju postali avtorjevo najbolj izdajano besedilo, se ne moremo čuditi, da je njihov aktualizacijski pomen, ki je zagotavljal tudi komercialni uspeh, že od prve knjižne izdaje leta 1886 pritegoval vrsto posnemovalcev in prirejevalcev. Znano je, da Jirásek ni bil pripravljen dati soglasja za dramatizacije in da je skrbno redigiral prevode svojih del; slednje je bilo v zvezi z estetiko kritičnega realizma, po kateri je treba imeti pod "nadzorom« recepcijsko usodo svojega teksta in prek ustaljene materializacije oziroma kanonizirane oblike zatreti neželene razlage ali interpretacijske variante. Pasjeglavci so v javnosti ne le izzvali kult Jana Kozine, temveč so

\footnotetext{
${ }^{4}$ Gre predvsem za Jiráskov Zápisník iz leta 1882. Shranjeno v: Literární archiv Památníku národního písemnictví v Praze, št. sign. T 1 A 4 (zapuščina A. J.). Pripombe k Pasjeglavcem so shranjene tudi v Materiáliich A. J. k románu Psohlavci. Shranjeno prav tam, št. sign. T 3 D 1.
} 
v prebivalcih Chodskega tudi prebudili zgodovinsko zavest (Roubík). Že v času revijalnega objavljanja romana je na Chodskem prihajalo do odkrivanja spominskih plošč in spomenikov; že leta 1895 je Myslbekov učenec Čeněk Vosmík v kraju Hrádek nad Újezdem postavil spomenik, ki je postal kultno mesto ljudskih manifestacij in narodnih proslav (Maur). Chodski upor je tako postal novodobni mit »krščanske dobe«, ki se je $s$ težnjo po izdajah $\mathrm{v}$ berilih uvrstil na panteon kanoniziranih narodnih povesti (prim. Juvan).

Leta 1897 je na natečaj za nagrado Društva narodnega gledališča skladatelj Karel Kovařovic na začetkih svoje kariere prijavil opero Pasjeglavci na libreto Karla Šípka po predlogi istoimenskega romana (Plavec 6). Jirásek je po dolgem kolebanju libretistu dal soglasje, tako da je šlo za dovoljeno dramatizacijo, ki ima značaj reprodukcijske, vendar obrtno posrečene adaptacije. Ta drugače od svojega izhodiščnega preteksta prenese čas fabule na leta 1695-1696 ter omeji število oseb in sekundarnih motivov (Zelenka 4). Tri dejanja v šestih slikah se osredotočijo na glavno zgodbeno linijo brez stranskega dogajanja. Libreto se tematsko zoži na priredbo mita o Kozinu kot simbolu chodskega upora v imenu človeških in narodnih pravic. Osebe nimajo notranjega razvoja in tudi njihovi medsebojni odnosi niso izdelani. Verzificirani dialogi so v knjižni češčini brez težje razumljivih narečnih prvin. Šípkov libreto, ki ga je Jirásek prebral in z drobnimi pripombami odobril, skupaj s Kovařovicevo dramatično glasbo, ki črpa iz smetanovske tradicije vključno z uporabo ljudske melodike, ustvarjata organsko celoto, neke vrste "uglasbeni roman" (Hostomská). Ta kljub delnim strukturnim spremembam ne spremeni tematske postavitve Jiráskovega preteksta in njegove aktualizacijske zasnove, ki so jo spodbudili tedanji političnimi dogodki. V času nastanka libreta, decembra 1897 , so bile razglašene izredne razmere za Prago in okolico kot reakcija na nacionalni upor, povezan z realizacijo Badenijevih jezikovnih naredb za Češko in Moravsko, ki so dopuščale češčino kot interni uradni jezik. Dolgotrajni češko-nemški boji so potem dva meseca pred uspešno uprizoritvijo opernih Pasjeglavcev 24. 4. 1898 privedli do Gautschevih jezikovnih naredb za Češko in Moravsko februarja 1898, ki so omejila vpliv češčine $v$ internem uradovanju.

Leto po Kovařovicevi operi je sledila še ena, tokrat nedovoljena dramatizacija z naslovom Jan Sladký Kozina (Pasjeglavci) Jana Baptista Kühnla (1848-1904), prevajalca in filologa, srednješolskega profesorja, ki je profesionalno prirejal tuje tekste za Prozatimní divadlo (Začasno gledališče). Kühnl, ki je občasno pisal pod psevdonimom Robert Veselý, je brez večjega odmeva zlagal tudi izvirne konverzacijske komedije, kot 
so Teta v ohni (Teta v ognju, 1884), Čupr na námluvách (Čupr dvori, 1886) ali Povedený Ferda (Posrečeni Ferdo, 1903) (Holub 1049). V tem primeru je šlo za očitno kršitev avtorskega zakona. Strokovna literatura o Jirásku je njegov pravni spor s Kühnlom in njegovo družino imela za marginalno, literarnozgodovinsko nepomembno zadevo, $s$ katero je opravila s površnimi omembami (Borecký; Janáčková; Voborník). V resnici pa ti spori ponujajo hevristično dragocen material za sociologijo sodobnega literarnega delovanja, ki razkriva ekonomski položaj pisatelja na prelomu 19. in 20. stoletja v povezavi z uveljavitvijo avtorskega zakona. Poleg tega literarnozgodovinsko dokumentirajo tudi primer reprodukcijske, pasivne adaptacije - plagiata brez estetske vrednosti.

Kühnl je svojo dramatizacijo Pasjeglavcev prvič predstavil v Švandovem gledališču na praškem Smíchovu 2. 4. 1899. Predstava od Jiráska ni dobila soglasja, ki je za inscenacijo izvedel šele iz časopisne novice in takoj reagiral. $\mathrm{V}$ pismu prijatelju in dramatiku Jaroslavu Kvapilu z dne 3. 4. 1899 sporoča, kako ga je razburilo, da je Kühnl delo reklamiral kot igro, narejeno po izvirnem romanu Pasjeglavci (Batha 110). Prosi Kvapila, naj v časopisa Zlatá Praha in Národní listy uvrsti notico, da se je "priredba mojega romana v dramo J. Kühnla zgodila brez mojega vedenja in soglasja» (Batha 110). Jirásek se je še istega dne povezal s svojim pravnim zastopnikom, odvetnikom Ladislavom Klumparjem (1863-1930), med drugim poslancem v državnem zboru na Dunaju, in ga pooblastil, da proti prirejevalcu Kühnlu sproži pravni postopek pred cesarsko-kraljevim deželnim kazenskim sodiščem $\mathrm{v}$ Pragi. Mladočeško usmerjeni Klumpar, med drugim poznejši poslanec v državnem zboru v letih 1904-1907, je spadal med najpomembnejše češke pravnike na prelomu 19. in 20. stoletja, bil pa je leta 1883 tudi avtor danes pozabljene pesniške zbirke $\mathrm{Na}$ prahu života (Na pragu življenja), ki epigonsko posnema lumírovsko poetiko, predvsem poezijo Jaroslava Vrchlickega (Klumpar).

Jirásek je v prvem sodnem sporu na prelomu 19. in 20. stoletja zmagal. Za preučevanje te sodne obravnave nimamo na razpolago ne tožbe ne drugih uradnih spisov; ohranjen ni niti pisateljev odziv v osebni korespondenci. Toda v zapuščini se je ohranila dokumentacija o drugem sodnem sporu med Jiráskom in družino Kühnl iz leta 1920. Ta je sledil po več kot dvajsetih letih, ko sta po Kühnlovi smrti njegova vdova Marie in hči Maria Luisa delo Jan Sladký Kozina (Pasjeglavci) leta 1920 ponovno izdali in je cela zadeva znova končala na sodišču. Ohranjena sodna dokumentacija vsebuje lastnoročno podpisano izjavo J. B. Kühnla z dne 13. 4. 1899, ki je na hitrem postopku pred sodiščem priznal neupravičenost svoje dramatizacije. Jedrnat tekst izjave $\mathrm{v}$ 
treh odstavkih ugotavlja, da podpisani [= J. B. Kühnl - op. M. Z.] »Za priredbo zgodovinske slike Pasjeglavci od Aloisa Jiráska ni imel dovoljenja $[\ldots]$ in da je priredil to igro $\mathrm{v}$ nasprotju $\mathrm{z}$ avtorskimi pravicami pisatelja«. ${ }^{5}$ Obenem potrjuje, da igre ni ne brezplačno ne za plačilo nikomur ni prepustil in da do sedaj ni dal nikomur soglasja za uprizarjanje. Izjavo je dopolnjevala klavzula o veljavnosti, predvidena le za primer izpolnitve poravnave po predhodnem dogovoru, ki pa ni konkretiziran ali komentiran. Tako ni mogoče ugotoviti, ali je bila sestavni del dogovora o poravnavi tudi finančna kompenzacija. Do poravnave je prišlo 20. 4. 1899, kar je Klumpar sporočil Jirásku z uradnim dopisom, ki pa v Jiráskovi zapuščini manjka. Glede na uprizoritev samo ene nedovoljene predstave lahko predvidevamo, da se je Jirásek zadovoljil z ukrepom prepovedi nadaljnjega uprizarjanja in svoje škode ni finančno opredelil.

Kühnl namreč igre na sceni Švandovega gledališča ni več uprizarjal, a jo je dve leti pozneje (leta 1901) na lastne stroške knjižno izdal pod naslovom Jan Sladký Kozina (Pasjeglavci) s podnaslovom "zgodovinska slika v 6 dejanjih, po češki zgodovini napisal Jan Baptist Kühnl« (Kühnl 2). Zamenjava konkretnega sklica na Jiráskov pretekst $s$ formulacijo "po češki zgodovini« naj bi zastrla povezavo z glavnim virom, kljub temu pa se iz primerjave obeh besedil nedvoumno kaže genetska odvisnost Kühnlove dramatizacije od Jiráskovega vzora, saj se giblje med neustvarjalno, pasivno reproduktivno imitacijo in plagiatom.

Priredba obsega 45 strani, v uvodu predstavi nastopajoče osebe, ki so v bistvu istovetne s tistimi v Śípkovem opernem libretu. Kühnl celo doda pouk o pravicah do uprizarjanja, ki so menda "pridržane» zanj kot avtorja, pisatelja na Královskih Vinohradih št. 706 (tudi sedež založbe), in to z opombo, da se "vsaka neupravičena izvedba preganja sodno (Kühnl 2). Za uprizarjanje igre, za katero je treba plačati vnaprej ali v treh dneh, je potrebno Kühnlovo soglasje, pri čemer v primeru njegove smrti pravice do uprizarjanja prehajajo na njegove dediče. Brezplačno se igra pod nobeno pretvezo ne sme uprizarjati niti za namene ljubiteljskih društev, ki igrajo v dobrodelne namene: "[...] tu pisatelj ne bi dobil ničesar. Zahtevajte le Kühnlovo izdajo« (Kühnl 76). Jirásek se na izdajo Kühnlove dramatizacije ni odzval, niti ni sodno ukrepal. Igra se namreč po letu 1899 ni uprizarjala, prvotna tožba pa poleg tega ni vsebovala klavzule o prepovedi izdaje teksta; pri-

${ }^{5}$ Spis obžalovaci Zemského trestního soudu v Praze z 12. 11. 1921 na pani Marii Kühnlovou a slečnu Marii Kühnlovou. Shranjeno v: Literární archiv Památníku národního písemnictví v Praze (zapuščina A. J.). 
redba je tedaj obstajala samo v rokopisu, ki ga je moral Kühnl v sklopu poravnave Jirásku odstopiti.

Če se vrnemo k primerjavi romana in dramatizirane priredbe, ugotovimo, da je prevzeta ne le idejno-tematska zasnova, temveč tudi kompozicijska struktura glavne dogajalne linije z jezikovno normo vred. Čas fabule 1895-1896 je skladen s Šípkovim libretom, osebe prav tako govorijo $\mathrm{v}$ knjižni češčini $s$ chodskimi narečnimi prvinami, dialogi razen izjem niso parafrazirani, temveč so dobesedno prepisani od Jiráskovih likov, in to brez pojasnila ali sklica. Sklenemo lahko, da istovetnost dogajalne linije (po skrajšanju refleksivnih delov), osnovana na dobesednih citatih, vodi $\mathrm{k}$ temu, da je fabula drame zgolj adaptacijska eliminacija, obrtniška okrajšava izvirnih Pasjeglavcev. Dramatizacija sicer odstopa od svojega preteksta, a pri tem ne gre za amplifikacijo, ki bi dramatizacijo razširjala z novimi motivi, temveč za kontaminacijsko kontrakcijo, ki več epskih motivov združi v en situacijski dogodek (Žilka), podobno kakor v Šípkovem libretu (npr. krajšanje več sodnih sporov v enega osrednjega). Plagiatorski značaj dramske priredbe je v Kühnlovem primeru očiten na prvi pogled. Iz teh dejstev je nedvomno izhajala odločitev Deželnega kazenskega sodišča v Pragi, ki je brez zavlačevanja sledila takoj po uprizoritvi nedovoljene inscenacije. Plagiat se je tedaj v praksi definiral zelo široko, o čemer priča geslo znanega češkega folklorista in etnologa v enciklopediji Ottưv slovnik naučný, in sicer kot "delna odtujitev intelektualnega izdelka, ki je znan kot rezultat predhodnega intelektualnega dela druge osebe« (Kubín 828). Čeprav geslo ponarejanja ni povezovalo $s$ predelavo tuje ideje in posledično genezo novega teksta, češ da »kulturni razvoj v celoti raste iz predhodnih temeljev« (prav tam), je sodišče v svojih odločitvah poudarjalo pomen neustvarjalnega prilaščanja brez soglasja izvirnega avtorja, katerega osebne pravice so bile na bistveni način kršene.

Drugi Jiráskov sodni spor s Kühnlovo družino, konkretno z vdovo Marie Kühnlovo (roj. 1854) in hčerko Marie Luiso (1891-1945), profesorico moderne filologije, iz leta 1921 se da natančneje opisati, ker se je v pisateljevi zapuščini ohranil spis Obžalovaci Zemského trestního soudu (Obtožnica Deželnega kazenskega sodišča) iz leta 1921. Približno trinajst let po smrti J. B. Kühnla leta 1904 sta Kühnlovi vdova in hči leta 1920 na lastne stroške v Českoslovaški delniški tiskarni izdali gledališko igro svojega očeta Jan Sladký Kozina (Pasjeglavci) (Kühnl). Ta tekst je z oznako sedma izdaja za natis revidirala in na novo uredila hči Marie Luisa. Jirásek, ki v tem obdobju ni bil le pisatelj, temveč tudi javna osebnost - senator za narodno demokracijo - je najverjetneje na začetku leta 1921 prek svojega pravnega zastopnika Adolfa 
Červinke poskusil skleniti dogovor: zahteval je pisno, $v$ časopisu objavljeno opravičilo, umik knjige iz distribucije in finančno nadomestilo za izgubljeni dobiček od prodaje in eventualnega uprizarjanja. Iz tožbenega spisa izhaja, da je tožena stranka za izdajo 3.000 izvodov (po izjavi tiskarne) plačala $2.574 \mathrm{Kč}$, pri čemer so toženi računali en izvod po $10 \mathrm{Kč}$, knjigarnarjem pa so ga prodajali s pribitkom 7,20 Kč. Ker nobena od Kühnlovih dedinj ni pokazala pripravljenosti na sporazumno rešitev zadeve, je Jirásek najverjetneje $\mathrm{v}$ drugi polovici januarja 1921 - točnega datuma namreč ni mogoče določiti - na policijski upravi podal pobudo za pregon s predlogom za kazenski postopek, kar je sodišče sprejelo.

Po uvedbi kazenskega postopka 16. 2. 1921 sta obtoženi - tako kot prej njun pokojni soprog oziroma oče $-\mathrm{v}$ izjavi priznali neupravičenost svojega početja, kar sta potrdili s svojim podpisom. Obtoženi sta se zavedali, da sta s predelavo, knjižno izdajo in uprizarjanjem že pred tem prepovedane igre prekršili Jiráskove avtorske pravice. Na lastne stroške sta morali v osrednji periodiki, predvsem v časopisih Národní listy, Národni politika, Venkov, České slovo, Právo lidu in v brnskem časopisu Lidové noviny, objaviti kratko izjavo, da se »kakršnokoli uprizarjanje te neupravičene priredbe Pasjeglavcev Jana B. Kühnla prepoveduje«(9). Sto dva zasežena izvoda, ki sta bila najdena pri preiskavi na domu obtoženih v ulici Slezská třída št. 84 na Královskih Vinohradih, sta morala biti predana $v$ hrambo odvetniku Červinku in posledično uničena. Nedovoljena obogatitev in nadomestitev škode sta bili ocenjeni na 700 Kč (Jirásek je nameraval ta znesek podariti pisateljskemu društvu Máj, katerega član je bil), dodatni stroški, nastali do dneva razglasitve sodbe, pa so znašali še dodatnih 410 Kč. Če bi obtoženi knjigo ponovno izdali, uprizarjali ali drugače javno širili, bi ponovno kršili avtorske pravice tožeče stranke, ki je imela pravico ponovno ukrepati na kazenskem sodišču in zahtevati dodatno kompenzacijo. Zaustavitev kazenskega postopka je bila možna šele po izpolnitvi vseh pogojev dogovorjene poravnave na obeh straneh. $V$ tožbenem spisu je shranjen dopis odvetnika Červinke vdovi Marii Kühnlovi z 12. 2. 1921, v katerem jo obvešča, da čeprav je dobil zahtevanih 700 Kč preko poštne nakaznice, kazenskega postopka ne gre zaustaviti, saj niso bili izpolnjeni vsi pogoji poravnave. Nasprotno, obtoženi se še naprej spuščata $\mathrm{v}$ protipravno ravnanje, ne sodelujeta s tožilcem, ki mu zavestno ne navajata resničnih podatkov. Kühnlova drama bojda ni izšla v šstevilu 1.500 izvodov, kakor sta priznali toženi, temveč v večji nakladi 2.000 izvodov. Kakor pa se je pokazalo pozneje, niti ta podcenjeni podatek ni bil pravi. Obtoženki sta račun iz tiskarne ponaredili s prepisom številke, 
$s$ čimer sta se obogatili še za dodatnih $2.000 \mathrm{Kč}$. Iz teh razlogov se ne da znižati celotne vsote nadomestila, ki pa v odvetnikovem dopisu ni natančno opredeljena. Obtoženki bi morali še pred glavnim soočenjem kazenskega postopka priti v odvetniško pisarno in finančno poravnati njegove stroške, stroške sodne komisije in podpisati pristojne dokumente. Nobena od zahtev ni bila izpolnjena: zahtevano opravičilo - pa še to v skrajšani verziji, ki je bilo dovoljeno - sta toženi objavili samo v popoldanski izdaji časopisa Národni politika z dne 3. 2. 1921, v druge periodike plačljive izjave nista poslali.

Čeprav je po februarju 1921 tožena stranka potrdila protipravnost svojega početja, se je igra vseeno priložnostno uprizarjala. $\mathrm{O}$ tem med drugim priča pripis policijskega direktorata $\mathrm{z}$ dne 28. 4. 1921, ki dokumentira verjetno število nedovoljenih inscenacij. Jirásek je zato ponovno vložil tožbo na Deželno kazensko sodišče v Pragi. Tožba, ki jo lahko preko ohranjenega Tožbenega spisa z dne 12. 11. 1921 podrobno analiziramo, je imela tri točke: 1 . nedovoljena prodaja 13 izvodov knjige 2. 3. 1921 Václavu Knappu v Karlínu in junija 1921 treh izvodov Kristini Schramlovi za društvo Orel v Jihlavi; 2. toženi sta še naprej dajali protipravna dovoljenja za uprizoritve in prejemali plačila med 50 in 80 Kč (tožba navaja konkretne uprizoritve $s$ točno datacijo in lokalizacijo na Češkem in na Moravskem); 3. nedovoljena izdaja igre v nakladi 3.000 izvodov in njeno zavestno razširjanje za plačilo, s čimer je prišlo do nedovoljenega posega "v avtorske pravice zasebnega tožnika" (3). Tožbeni spis nato predlaga seznam prič in navaja druge dokazne materiale, obenem pa opominja na proces iz leta 1899 , ko je bil J. B. Kühnl tožen zaradi predelave svoje dramske igre. Tožba zato opozarja, da kljub namerni zamenjavi omembe "po romanu Aloisa Jiráska«s formulacijo "po češki zgodovini", nova predelava po členu 24, št. 3 zakona o avtorskih pravicah "ponavlja tožnikovo delo Pasjeglavci in njegove odlomke tako zelo, da sámo nima lastnosti originalnega dela«(6).

Medtem ko so pravne formulacije tožbenega spisa nedvomno odvetnikove, je verjetno dokazno primerjavo med pretekstom in dramatizacijo $\mathrm{v}$ obliki konzultacije prispeval sam Jirásek, saj natančno navaja prepisane povedi in odstavke. Tožba, ki podrobno analizira ujemanje besedil in dobesedne citate, namreč kaže literarnozgodovinsko erudicijo, ko opozarja na identičnost glavnih oseb, njihovega števila in karakterizacije, prevzem motivno-kompozicijske strukture s poudarkom na prevzeti koncepciji in zaključnem prizoru »božje sodbe«. Sklep strokovne analize je nedvoumen: "Zasebni tožnik je v svojih avtorskih pravicah občutno oškodovan, kajti delo Jana B. Kühnla je z literarnega stališča pravi plagiat, ki brezobzirno jemlje iz tožnikovega dela 
celotno zgradbo, fabulo romana in njegove posamične dele«. ${ }^{6}$ Obtožnica v zaključku poudarja, da je bila toženima krivda večkrat dokazana $s$ podpisanimi potrdili, izpovedmi prič in z lastnoročnim priznanjem. Kljub temu svoje krivde ne priznavata $\mathrm{v}$ polnem obsegu in neprenehoma iščeta možnosti nadaljevanja svojega protipravnega početja, zato je tožba popolnoma utemeljena in upravičena.

Do zaključne sodne obravnave je prišlo 7. 2. 1922. Čeprav nimamo na razpolago zapisnika obravnave $-\mathrm{v}$ Jiráskovi zapuščini se namreč ni ohranil -, novica v časopisu Národní listy z dne 8. 1.1922 povzame zaključek spora (Zákaz 6). Ta je bil razrešen z novo izjavo, v katerem toženi priznavata, da sta zavestno kršili avtorski zakon, in se strinjata $\mathrm{z}$ definitivno prepovedjo nedopustne predelave Pasjeglavcev, ki ne ustreza "niti skromnim umetniškim zahtevam" (prav tam) in temelji na pasivni reprodukciji celotnih scen. Toženi obenem soglašata z uničenjem vseh zaseženih izvodov in se zavezujeta povrniti zagovorniku in tožniku 800 Kč v štirih mesečnih obrokih. Priznavata, da »[...] vsako nadaljnje uprizarjanje in razširjanje drame ponovno krši avtorske pravice (prav tam). V izjavi za tisk, ki se odziva na jok tožene Marie Kühnlove pred senatom, je zagovornik Červinka navedel, da gre tožeči strani samo za "načelo, da se z literarno lastnino ne sme ravnati samovoljno" (prav tam). Poročevalcu Národnih listov se je posrečilo dobiti tudi izjavo samega pisatelja, ki se zaključnega soočenja presenetljivo ni udeležil; Jirásek menda "ne zagovarja manj pomembnih interesov, temveč le literarne interese. Kühnlova predelava Pasjeglavcev je slaba« (prav tam).

O Jiráskovi zmagi v dolgotrajnem sodnem procesu priča dejstvo, da Kühnlova dramatizacija Jan Sladký Kozina (Pasjeglavci) ni bila več izdana in da je češke ljubiteljske in profesionalne gledališke skupine niso več uprizarjale. Na prvi pogled je Jiráskov spor z umetniško nepomembnimi plagiatorji, katerih imen dandanes ne poznajo niti specializirani literarni zgodovinarji, lahko videti kot banalna epizoda v biografiji slavnega pisatelja: njegova finančna škoda je bila zanemarljiva, ni bil eksistencialno ogrožen, tudi do upada njegove avtoritete ali popularnosti med bralci ni prišlo. Kljub temu ima ta epizoda širši pomen: prvič v zgodovini češke literature je bil uporabljen novi avtorski zakon, ki ga je sodišče v Jiráskovem primeru tolmačilo ne le kot kršitev razpolagalnih (lastninskih) pravic, temveč tudi kot poseg v osebne pravice. Od tod je izviralo tudi dotlej neuporabljeno razlikovanje med lastnikom kot

${ }^{6}$ Spis obžalovací Zemského trestního soudu v Praze z 12. 11. 1921 na paní Marii Kühnlovou a slečnu Marii Kühnlovou. Shranjeno v: Literární archiv Památníku národního písemnictví v Praze (zapuščina A. J.). S. 8. 
nosilcem materialnih in avtorjem kot nosilcem moralnih avtorskih pravic. Obenem je v tem primeru sodišče - najverjetneje s pomočjo strokovne konzultacije - opredelilo "pravi plagiat" na podlagi njegovega odnosa do originala. Če pustimo v oklepaju pravno plat obeh procesov, ki sta potekala v razmiku več kot dvajset let, interes prirejevalcev za Jiráskove Pasjeglavce s Kühnlovo priredbo vred potrjuje bralsko priljubljenost enega od ikoničnih tekstov tega avtorja. Tudi "pravi plagiat«, kakor ga je kvalificirala obtožnica, ostaja v bistvu simptomatična oblika kontinuitetne intertekstualne izpeljave in literarne recepcije, ki sodi med redkejše in nižje prvine literarne kulture.

\section{LITERATURA}

Adámek, Karel Václav. O právu autorském. Brno: Moravská akciová knihtiskárna, 1898.

Batha, František, ur. Alois Jirásek. Dopisy 1871-1927. Praga: Muzeum Aloise Jiráska Orbis, 1965.

Borecký, Jaromír. Alois Jirásek. Praga: Česká akademie věd a umění, 1933.

Cuřín, František. "Ke vzniku Jiráskových Psohlavců«. Časopis pro moderni filologii 29 (1946): 30-38.

Filová, Klára. K textovému vývoji Psohlavcu a jeho adaptováni (originál a kopie v procesu autorizace). České Budějovice: Pedagogická fakulta Jihočeské univerzity, 2018 (diplomsko delo).

Hermann-Otavský, Karel. O právni ochranè ideálních zájmů autora díla literárního a uméleckého v právu rakouském. Praga: samozaložba, 1904.

Hodura, Quido. »Jiráskovi 'Psohlavci' a 'Chodská pře' od J. L. Weisela«. Česká literatura 5 (1957): 87-94.

Holub, Dalibor. "Jan Baptist Kühnl«. Lexikon české literatury. Osobnosti, dila, instituce. 2./II. K-L. Ur. V. Forst. Praga: Academia, 1993, 1049-1050 (podpisano dh).

Hostomská, Anna. Opera. Priovodce operni tvorbou. Praga: Státní nakladatelství krásné literatury, hudby a umění, 1955.

Janáčková, Jaroslava. Alois Jirásek. Praga: Melantrich, 1987.

Jílek, Václav. Deset kapitol o Jiráskových Psohlavcích. Praga: Státní pedagogické nakladatelství, 1959.

Juvan, Marko. »'Slovenski kulturni sindrom' v nacionalni in primerjalni zgodovini«. Slavistična revija 56.1 (2008): 1-17.

Kadlec, Karel. Poćátky práva autorského: studie o vzájemných pomèrech tiskarù a spisovateli̊ $v$ minulých stoletich. Praga: samozaložba, 1893.

Klumpar, Ladislav. Na prahu života: básnè Svatopluka Orlického. Praga: S. Orlický, 1883.

Kramařík, Jaroslav. Kozina a Lomikar v chodské lidové tradici. Praga: Academia, 1972. Kubín, Josef Štefan. »Plagiat«. Ottův slovník naučný. Devatenáctý dill. Praga: J. Otto, 1902 (podpisano Kbn.).

Kühnl, Jan Baptist. Jan Sladký Kozina (Psohlavci). Praga: Kühnl, 1901.

Maur, Eduard. Kozina a Lomikar. Praga: Melantrich, 1989.

Moravec, Josef. "Několik dopisů Aloise Jiráska Jaroslavu Vrchlickému z let 18731885«. Česká literatura 1 (1953): 83-95. 
Plavec, Josef. „Psohlavci ve vývoji české opery«. Národní divadlo 26 (1950-1951): 5-9. Pospíšil, Ivo, in Zelenka, Miloš. »Sociologie literatury a komparatistické impulsy Karla Krejčího v meziválečném období (mezi sociologismem a strukturální estetikou)«. Karel Krejči: Sociologie literatury. Ur. Ivo Pospísil in Miloš Zelenka. Praga: Grada Publishing, 2008. 7-50.

Roubík, František. Dějiny Chodi̊ u Domažlic. Praga: Ministerstvo vnitra Republiky Československé, 1931.

Simon, Josef. "Z korespondence Aloise Jiráska s Antonínem Truhlářem«. Slovesná véda 5 (1952): 75-78.

Sýkorová, Pavla. Autorské právo v praxi. Praga: České vysoké učení technické, 2019.

Špét, Jiř́i. »Z dopisů Aloise Jiráska Antonínu Rezkovi«. Slovesná věda 4 (1951): 143-147.

Voborník, Jan. Alois Jirásek: jeho umělecká ciinnost, význam a hodnota díla. Praga: J. Otto, 1901.

Zákaz Kühnelova dramatického zpracování »Psohlavců». Národní listy 8. januar 1922: 6. Zelenka, Miloš. „Karel Kovařovic. Psohlavci«. Národni divadlo informuje 50 (1985): 4. Žilka, Tibor. Text a posttext: cestami poetiky a estetiky $k$ postmoderne. Nitra: Ústav literárnej a vedeckej komunikácie Filozofickej fakulty Univerzity Konštantína Filozofa v Nitre, 2011.

\section{Copyright in Czech Literature at the Turn of the Twentieth Century: Jirásek's Quarrel Over Psohlavci}

Keywords: literature and law / Czech literature / literary history / copyright / Jirásek, Alois / theatre adaptations / Kühnl, Jan Baptist / plagiarism

The article examines the unauthorised stage adaptation of Alois Jirásek's novel Psohlavci (Dogheads) produced by Jan Baptist Kühnl (1849-1904), a dramatist, translator, and one of the earliest plagiarists in the late nineteenth-century Czech literature who in 1899 adapted and without authorisation staged the play Jan Sladký Kozina (published as a book in 1901). Kühnl's adaptation was completed without the permission of Jirásek, who intervened against the play's illegal enactment at Švanda's Theatre in Smíchov through his lawyer Ladislav Klumpar (1863-1930), an imperial deputy. Jirásek won the 1899 trial by virtue of Act \#197/1895, which continued the 1846 Imperial Patent, defining the nature and realisation of artistic creations (whose wording was partially incorporated into the Copyright Act of independent Czechoslovakia). In 1920, the play Jan Sladký Kozina was republished on behalf of Kühnl's descendants, his widow Marie Kühnlová and daughter Marie Luisa Kühnlová 
(1891-1945), a translator from Romance languages who only modernised the original 1899 epigonic adaptation for amateur actors. The second lawsuit in 1921 was not only Jirásek's victory but it fully demonstrated that copyright was a relevant manifestation of intellectual intangible assets which must be legally protected. From a literary perspective, the case offers an interesting illustration of the contemporary concept of plagiarism as uninventive imitation, borrowing "thoughtlessly the whole structure, storyline and even individual elements" of a work.

1.01 Izvirni znanstveni članek / Original scientific article

UDK 821.162.3.09:347.78

DOI: https://doi.org/10.3986/pkn.v43.i2.08 